\title{
$O$ estabelecimento das escolas noturnas baianas no final do século XIX
}

\author{
Jucimar Cerqueira*
}

Palavras-chave:

Escolas noturnas

Educação

Instrução
Keywords:

Night schools

Education

Education
Resumo: O objetivo desse artigo é discutir como o discurso de autoridades políticas e "educacionais" buscaram legitimar a criação e organização das escolas noturnas na Bahia para trabalhadores adultos nas reformas educacionais da década de 1870, utilizando argumentos a partir de demandas políticas, sociais e econômicas da época. Essa discussão será feita a partir do cruzamento entre fontes como as correspondências de professores aos diretores da Instrução Pública e aos presidentes da Província, os relatórios de presidentes da Província e a bibliografia escolhida sobre a época.

Abstract: The objective of this article is to discuss how the discourse of political and educational authorities sought to legitimize the creation and organization of night schools in Bahia for adult workers in the educational reforms of the 1870s, using arguments based on the political, social and economic demands of time. This discussion will be based on the intersection of correspondence between teachers and the directors of the Public Instruction and the presidents of the Province, the reports of presidents of the Province and the bibliography chosen on the time.

Recebido em 15 de agosto de 2016. Aprovado em 13 de dezembro de 2016.
A instrução merece os cuidados da Constituição brasileira, ela é a base de todo o progresso, a condição essencial das instituições políticas de um povo livre, especialmente para si consagrar o voto quase universal nas urnas. Sem a leitura e a arte de escrever não pode o cidadão tomar parte ativa nos diferentes processos de eleição, nos conselhos da guarda nacional e na importantíssima instituição do júri. Cada baiano tenha um coração cheio de sincero patriotismo, cumpra tranquilo o seu dever; estude os homens, sua vida, seus precedentes e quando descobrir o seu bem intencionado, o experiente, siga-o e o auxilie no esforço pela regeneração do país. (MARTINS, 1869).

A partir da fala do Presidente provincial, é possível perceber como algumas autoridades políticas da época viam a educação e a quais propósitos políticos e sociais ela estava destinada. Era uma época de consolidação de uma independência em menos de 50 anos proclamada, daí a necessidade intensa de elaborar o que passaria a ser a nação brasileira.

Primeiramente, é importante pontuar que, no final do século XIX, ocorreram algumas transformações interligadas entre o cenário político, econômico e social do Brasil. O país saía de guerra contra o Paraguai, o movimento republicano estava em ascensão, a cultura produtora de café estava em desenvolvimento no vale do Paraíba e no Oeste paulista, as leis que visavam ao fim da escravidão estavam surtindo efeitos, com vários artigos que possibilitavam alforrias a escravizados, e a consolidação da emancipação brasileira ganhava mais vigor com a ideia de formação nacional, a partir de princípios como "progresso", "modernização", "desenvolvimento" e "civilização" (CARVALHO, 2003).

Nesse contexto, duas reformas educacionais na Bahia foram elaboradas e, sob a ideia de que era

\footnotetext{
* Professor do Instituto Federal de Educação, Ciência e Tecnologia da Bahia e Mestrando em História Social pela Universidade Federal da Bahia,

E-mail: jucimar18@yahoo.com.br
} 
preciso ter qualificação profissional por meio da instrução elementar associada ao "desenvolvimento" brasileiro. As escolas, também chamadas de aulas ou cursos noturnos para trabalhadores adultos, foram criadas em muitas outras províncias, conforme constam em estudos sobre as de Sergipe, Maranhão, Pernambuco, Alagoas, Pará, Amazonas, Goiás, Espírito Santo, Rio de Janeiro, São Paulo, Rio Grande do Sul e Paraná. Fato que aponta para uma escolarização imperial (MOACYR, 1939).

Nesse período, a instrução era a aprendizagem de saberes e técnicas para que fossem colocados em prática, tanto na atuação das atividades laborais de trabalhadores, quanto na influência desses sujeitos em ações políticas e de cidadania, como o direito ao voto. Já o termo educação era voltado à aprendizagem de valores e princípios morais, com forte atuação na doutrina cristã católica oficializada no Império brasileiro. Perceberemos que a ideia de instrução esteve mais fortemente ligada ao estabelecimento das escolas noturnas; pois, sendo voltada às atividades profissionais, ela era mais para a aprendizagem de técnicas aplicáveis ao universo daquele cotidiano de trabalho. Entretanto, em alguns momentos, a própria documentação do período não estabelece tão rigidamente a diferenciação entre os dois termos e muitas vezes a palavra "educação" é utilizada como um termo geral, e aplicada também para se referir ao que se chamou de instrução no século XIX (MATTOS, 2004).

$\mathrm{Na}$ Bahia, Francisco Gonçalves Martins afirmou que a instrução era "[...] a base de todo o progresso, a condição essencial das instituições políticas de um povo livre, especialmente para se consagrar o voto quase universal nas urnas" (MARTINS, 1869). E assim, ele propôs uma reforma educacional onde recomendou publicamente a frequência de adultos às escolas noturnas: "Os adultos, cujos pais não puderam proporcionar-lhes bem tão importante resignam-se com dificuldade à sua mesquinha sorte e em muitos lugares correm às aulas noturnas" e que as escolas noturnas “[...] ampliassem o progresso, colaborando no desenvolvimento da província, na nossa estatística, nos nossos costumes, no bem público e do país" (MARTINS, 1870, p. 4).
Algumas dessas aulas noturnas foram estabelecidas pelo governo provincial, muitas por professores particulares e outras por algumas associações de trabalhadores. Elas foram criadas com o objetivo de proporcionar o acesso às primeiras letras aos trabalhadores analfabetos e aos com poucos conhecimentos de leitura, escrita, cálculos, princípios cristãos católicos e desenho básico, além de algumas oferecerem matérias específicas de determinadas áreas profissionais, como foi o caso das aulas noturnas do Liceu de Artes e Ofícios da Bahia, da Sociedade Propagadora da Instrução às Classes Operárias da Lagoa, no Rio de Janeiro e da Sociedade dos Artistas Mecânicos e Liberais recifense (LEAL, 1996; SCHUELER, 1997; MAC CORD, 2012).

Francisco Gonçalves Martins enviou um relatório anual à Assembleia Legislativa provincial da Bahia em 1869 e nele informou: o "mal que estava embaraçando o progresso era, principalmente, a instrução primária, tão essencial e garantida pela Constituição". Ele também afirmou estar "penalizado com o atraso da instrução pública" em geral e, pela segunda vez na presidência da província, comparou a educação em seus dois governos (1848 a 1852 e 1868 a 1871) considerando que não houve "nenhuma vantagem colhida [naqueles] anos". Para resolver situações do tipo, ele ponderou que fosse viável uma reforma educacional na província e a propôs apresentando o interesse em melhorias na Instrução Pública; por isso, convocou uma equipe de representantes políticos e educacionais visando ao aprimoramento da formação e do trabalho docente, a criação de mais escolas e a redução no analfabetismo (MARTINS, 1869).

A comissão responsável pela elaboração da reforma educacional foi composta pelo Dr. Abílio César Borges, ex-diretor geral dos estudos na Bahia e da Sociedade abolicionista Sete de setembro, diretor do Ginásio da Bahia e político do partido conservador; o desembargador Manoel Joaquim Bahia, presidente do conselho superior de instrução e deputado eleito pela província para o parlamento nacional; e o Dr. João José de Oliveira Junqueira, deputado provincial pela Bahia por muitos anos e expresidente de várias províncias (MARTINS, 1869). 
Os dois políticos dessa proposta de reforma que mais se destacaram na educação e na política baiana da época foram Francisco Gonçalves Martins e Abílio César Borges. Sabendo algumas informações sobre o trajeto pessoal, político e o papel que esses sujeitos exerceram na educação, é possível compreender características da reforma em discussão.

Francisco Gonçalves Martins foi um senhor de engenho como seu pai, nascido na freguesia de São Pedro do Rio Fundo, no município de Santo Amaro, em 1807. Ele foi bacharel em leis pela Universidade de Coimbra e Juiz de Direito da comarca de Salvador. Entre 1833 e 1848, foi nomeado Desembargador do Tribunal da Relação da Bahia, assim como Deputado Provincial três vezes, chefe da polícia, barão e visconde de São Lourenço (WILDBERGER, 1949).

Além de ser político e proprietário de terras, Martins foi acusado de ser um dos grandes traficantes de escravos, conforme o jornal $\mathrm{O}$ guayacuru denunciou em 1851. No jornal, o político foi chamado de "o rei dos negreiros", pois era visto com traficantes e também responsável pelo transporte de africanos para o seu engenho, o São Lourenço (O GUAYACRU, 1851). Ele também foi Ministro no gabinete presidido pelo Visconde de Itaborai e, foi grande no Império, sendo comendador na Ordem de Cristo e conselheiro de sua Majestade. (WILDBERGER, 1949). Um político de destaque nacional foi o mentor de uma reforma educacional na Bahia que pretendeu combater o que ele chamou de "atraso da instrução".

Segundo Luís Anselmo da Fonseca, Martins defendeu a instrução profissional em detrimento do trabalho escravo, embora fosse um proprietário de terra e de escravizados, afirmando que:

[...] depois de muitos anos agito a questão da necessidade de cessação da escravidão e com especialidade tratei do objeto em sessões do Instituto Agrícola, fazendo ver que a luta americana se resolveria pelos Estados do Norte (EUA), sendo a consequência da vitória a extinção da escravidão. A instrução profissional é o meio mais eficaz que deve estar a cargo das escolas e estabelecimentos especiais. (FONSECA, 1887, p. 214).

Martins finalizou sua declaração típica de alguns políticos conservadores da época que almejavam o fim da escravidão sem causar prejuízos econômicos aos proprietários, dizendo que "[...] se o governo pretende fazer sacrifícios para fundar colônias de melhores raças humanas, prefira preparar a nossa para o trabalho, mediante a maior instrução possível”, preparando a mão de obra para o Brasil que se tornaria "moderno" (FONSECA, 1887, p. 271).

Martins foi integrante da elite econômica e política baiana, proprietário de escravizados, acusado de traficar pessoas, político autoritário associado e defensor da instrução para trabalhadores das camadas populares, incluindo escravizados e libertos. Era uma pessoa de características que evidenciam as várias possibilidades dos sujeitos com seus dilemas e suas contradições, seus objetivos e posicionamentos, como o interesse sobre os que seriam os "homens nacionais" naquele período de declínio de escravidão, argumento que reitera a proposta de educação para "regeneração" do país e seus integrantes e, não necessariamente uma solidariedade a pessoas que não tinham sua força de trabalho livre para usar como bem quisessem. A postura de Martin evidencia as diversas configurações que tiveram a busca pelo fim da escravidão no Brasil.

Já Abílio César Borges, o barão de Macaúbas, nasceu na cidade de Rio de Contas, em 1824. Ele fez faculdade de Medicina no Rio de Janeiro, foi professor e diretor do Ginásio da Bahia entre 1858 e 1871 e presidente da câmara municipal de Barra, onde fundou e dirigiu o colégio Ateneu Barrense. Assim como Martins, Borges também foi comendador da Ordem de cristo. Além de participar na elaboração da reforma de 1870, foi diretor de escolas particulares e autor de livros didáticos, inclusive, doou 2 mil exemplares à Instrução Pública baiana para serem usados nas escolas noturnas (COUTO, 1873).

Para Carlos Eduardo Souza (2015), Borges via na instrução a chave para a emancipação do povo, 
assim como integração dos libertos à sociedade e ao mundo do trabalho nacional. Entretanto, sendo um político do partido Conservador, percebe-se mais uma evidência que a ideia de liberdade possui várias acepções e para Borges essa palavra tinha dimensões diferentes do que para um escravizado, obviamente, bem como para um político do partido Liberal. Dessa forma, ele, assim como Martins, apresentou muito mais possibilidade de defender a "instrução popular” em uma perspectiva mais próxima das melhorias advindas com o "progresso", formação nacional, "civilização" e "regeneração" dos grupos sociais oriundos da escravidão, do que um anseio por uma melhoria na condição social desses grupos ao ponto de ocuparem posições de poder como essas autoridades.

Antes de discutir as reformas educacionais baianas que ensejaram a existência das escolas noturnas, é preciso conhecer como estava organizada a educação naquela província, para compreender em que contexto educacional as escolas para trabalhadores diurnos foram criadas.

\section{A educação baiana do período}

A organização educacional no Brasil partia de uma instituição chamada Instrução Pública, setor responsável pela direção geral da educação em cada província, inclusive, nos casos de escolas diurnas, das aulas particulares, do nível secundário e superior de ensino. Seu principal responsável era o diretor geral, que era chefiado pelo Presidente da Província. Segundo José Carlos de Araújo Silva, a Instrução Pública centralizava o direcionamento da educação nas províncias, ela foi oficializada com o decreto imperial de 1827 e em 1834 por meio do Ato Adicional à Constituição de 1824, passou a ser responsabilidade de cada província e não mais somente do império (SILVA, 1999).

A instrução das primeiras letras tinha como forma de ensino, no início do século, o método mútuo, monitorial ou lancasteriano, que foi implantado no Brasil pelo Decreto Imperial de 15 de outubro de 1827. Esse método funcionava de maneira que os alunos mais adiantados nos conteúdos eram indicados pelos professores para ensinar aos demais; assim, a turma era dividida em classes, de acordo com o nível de conhecimento de cada uma. Silva (1999, p. 111) aponta que esse método de ensino predominou na educação brasileira na primeira metade do século XIX e afirma que tinha ligação com o "[...] advento da produção industrial na Europa e com a necessidade de formação de uma mão de obra mais bem qualificada, eficiente e disciplinada para a rotina fabril".

O Decreto Imperial de 1827 estabeleceu critérios determinantes para a educação brasileira no século XIX, como o modelo das primeiras letras, o ensino mútuo e a proposta de ensino que buscava dividir a responsabilidade da educação brasileira entre os poderes públicos e os cidadãos particulares dispostos a lecionarem, a liberdade de ensino. Critérios estes que foram efetivamente aplicados na prática escolar (SILVA, 1999).

A liberdade de ensino determinava que todo cidadão que comprovasse conhecimento e moralidade no que estava se propondo a ensinar, mediante apresentação de atestado assinado pelo pároco da freguesia, poderia abrir aulas particulares e se responsabilizaria por todo custeio das aulas. Esse princípio visava a um aumento de acesso à escolarização pela grande necessidade de alfabetização do período, não acrescentando gastos aos setores públicos com educação e desencadeando a criação de várias aulas autônomas (SILVA, 1999).

Segundo Silva, a partir do Decreto de 1827, foram constantes as solicitações para abrir escolas em todas as localidades das províncias. "As solicitações para a abertura dessas escolas partiram das autoridades religiosas, das Câmaras Municipais e dos moradores das localidades, estes intermediados na maioria das vezes pelos padres ou pelos próprios professores" (SILVA, 1999, p. 74). No ensino particular, houve medidas - primordialmente, de caráter filantrópico - ministradas por particulares e instituições religiosas, escolas privadas onde existia a cobrança de taxas aos pais e alunos, no caso de adultos, e que eram pouco frequentadas. Sobre essas taxas, eram constantes os relatos dos professores quanto à sua regularidade ou não pagamento. E o Decreto Imperial estabeleceu que 
o concurso público como forma de ingresso no magistério oficial. Conforme descrito em lei: "Os presidentes, em conselho, farão que se examinem os pretendentes, cujo ato deve ser público e nomearão professores, preferindo os de melhor conduta e instrução" (MOACYR, 1939, p. 41).

Segundo um regulamento provincial de 1842 , era preciso ter um bom comportamento moral, político e religioso, comprovado com documentos autênticos e das autoridades do lugar. Era necessária a certidão de folha corrida, que era um documento que "descrevia" sobre a moralidade do cidadão, assim como um comprovante de que o candidato não padecia de moléstia contagiosa, a certidão de ter frequentado a Escola Normal (instituição criada pelo Estado brasileiro para a formação professores) e ter sido aprovado nas matérias que ensinaria (SILVA, 1999).

Nesse período, havia o argumento da necessidade de formar alunos para o trabalho com conhecimentos que garantissem habilidades para a leitura de manuais, o cálculo de pesos e distâncias. Conforme salienta Silva (1999, p. 111), a instrução no período imperial esteve relacionada, também, com a concepção de progresso, questão que foi a tônica dos "discursos dos deputados que defendiam a necessidade de um sistema público de ensino" como um dos motivos para incentivar a educação de milhares de analfabetos para a estruturação de uma nação após sua emancipação de Portugal.

Sobre o nível secundário, Sara Dick (2001) informa que esse nível possuía menos vagas e o Liceu provincial era o único estabelecimento público responsável por ele na Bahia. Poucas pessoas estudavam ou o alcançavam e ele não era obrigatório. Fato que evidencia a restrição de acesso à educação a quantidades maiores de pessoas em relação às que possuíam acesso às primeiras letras (DICK, 2001)

Esse era o cenário da educação primária e secundária na Bahia entre o pós-independência e início do declínio do império. Nesse tempo, medidas voltadas à instrução primária de uma quantidade maior de pessoas foram defendidas.

\section{Uma discussão sobre os regulamentos educacionais que propuseram as escolas noturnas em 1870 na Bahia}

Em 4 de março de 1870, o Barão de São Lourenço, Francisco Gonçalves Martins, sancionou uma reforma no ensino baiano por meio da Resolução no 1.116, com a ideia de "modernização da instrução e autonomia do país". Para esses argumentos, ele tinha como referência Inglaterra, Escócia, Suíça e, principalmente, Estados Unidos, "[...] pelo esmero na valorização da educação para o trabalho como primordial para o desenvolvimento nacional" (MARTINS, 1870).

A partir da ideia da necessidade de ampliação de oportunidades de ensino e do discurso de consolidação da emancipação brasileira em relação a Portugal é possível compreender a fala de Martins informando que: "[...] uma nação que não tem conquistado sua liberdade por sacrifícios, que como a nossa a recebeu em um dia, por um só ato do poder, tem necessidade de assegurar esta liberdade tornando-se digna de a possuir" (referese aos atos de proclamação da independência). Então, era preciso fazer valer e efetivar a autonomia pelo processo de independência iniciado no Brasil (MARTINS, 1870).

$\mathrm{Na}$ reforma de 1870, foi estabelecida uma intensa fiscalização para o comportamento e compromisso dos professores no cotidiano das aulas. Caberia à direção geral da instrução, ao conselho superior de instrução, ao inspetor geral e do conselho municipal fiscalizar como as aulas aconteceriam, assim como a frequência de todos que participavam das escolas, o rendimento dos alunos e a forma como os professores transmitiriam os conteúdos, com a emissão de um mapa de aulas anual. O mapa de aulas, que foi estabelecido como obrigação para todos os professores do império, deveria conter diversos dados, tais como: quantidade de alunos matriculados, nomes, naturalidade, idades, sexo, onde moravam, filiação e desempenho nas aulas. Alguns mapas mencionavam até se os alunos eram vacinados contra varíola, mais um elemento que evidencia a conexão das demandas educacionais com alguns princípios defendidos 
na sociedade da época, como o de sanitarismo (CHALHOUB, 1996).

Na reforma, também consta a associação entre instrução e trabalho; isso acaba evidenciando o interesse daquelas autoridades em intensificar a frequência nas escolas a partir do seguinte trecho: "[...] nos países onde o trabalho era a primeira condição, onde o desenvolvimento material se descobria nas diferentes indústrias, o ensino era mais amplo" (MARTINS, 1870). Martins exemplificou o seu plano de reforma usando os Estados Unidos como principal referencial:

[...] os pais eram punidos quando não faziam dar [instrução] a seus filhos; nós não podemos chegar ainda a este grau de perfeição a que a sociedade tem direito, onde se vê que o maior número de criminosos são analfabetos; porém, a reforma espera chegar a meio caminho, e o alcançará se puder auxiliar a favorável inclinação dos pais. (MARTINS, 1870, p. 3)

Analfabetismo e crime foram apontados como causa e consequência no decreto educacional baiano de 1870. A escolarização é considerada, já naquela época, como capaz de impedir atos criminosos pelos alunos. Desse modo, a reforma educacional de 1870 assumia um tom fiscalizador que previa acompanhar o trabalho dos professores e o afastamento dos alunos da criminalidade, direcionando-os ao trabalho através de outro elemento dito como necessário àquela sociedade em vias de fins da escravidão: o controle social.

Segundo Ione Celeste de Sousa (2006), as leis emancipacionistas estavam no centro das atenções do Estado brasileiro com a Instrução Pública. Ele passou a incorporar outros sujeitos em suas preocupações - o liberto e o ingênuo -, sempre visando a "[...] prepará-los como trabalhadores morigerados e úteis à pátria, leia-se dedicados ao trabalho, pouco reivindicatórios e cordatos" (p. 32) para não causar o prejuízo da correção de crimes. Essa perspectiva apontada por Sousa está voltada não só à busca por autonomia da nação em formação mas ao interesse em conter, também, grupos sociais por meio da instrução pública desde o ensino de doutrina cristã, até as aulas sendo regidas e inspecionadas intensamente pela direção da Instrução Pública.

A década de 1870 foi marcada por agitações políticas e sociais em torno do fim da escravidão no Brasil. Sidney Chalhoub aponta que as discussões políticas que culminaram com a Lei de 1871, a do ventre livre, tiveram, entre suas pautas, aspectos que proporcionariam cartas de alforrias como o fundo de emancipação, o fim da possibilidade de revogação dessas cartas e o fato de escravizados recorrerem à justiça por terem sido traficados após a Lei de 1831, que previa a ilegalidade do trânsito de africanos para o Brasil. Esses elementos tiveram como consequência uma grande quantidade de alforrias a partir de muitos esforços de escravizados e abolicionistas, contra a resistência de interesses senhoriais em retardar, ao máximo, a libertação que traria o fim do cativeiro para muitos homens e mulheres (CHALHOUB, 2003).

Jailton Lima Brito (2003) aponta que, na década de 1870, na Bahia, havia uma formação da movimentação abolicionista, que teve seu ponto alto na década seguinte. A ideia de educação para as populações escravizadas, libertas e livres estavam no bojo da proposta de educar e instruir a grande da população brasileira que era analfabeta.

A educação era uma das pautas que também ganhou mais incentivo com a presença do público de libertos, daí pensar nesses sujeitos como potenciais alunos das escolas noturnas, pois já integravam há muito tempo e, desde a condição de escravidão, os grupos de trabalhadores diurnos da época. Mendonça (1999, p. 71) aponta que a inércia do Estado para promover tal "proteção" aos libertos deixava aos encargos dos senhores, não somente na forma de cuidados mas também de "educação" para a liberdade no trabalho.

Nessas discussões políticas e sociais da década de 1870, outro ponto de destaque da reforma da educação baiana de 1870 sobre as primeiras letras foi a preocupação com a formação política do cidadão, o que poderia significar o seu direcionamento para atender a interesses políticos ligados a relações pessoais da época, mas também a possibilidade de autonomia dos 
sujeitos através do poder de decisão política pelo voto (CHALHOUB, 2003). A ideia de formação cidadã também se apresentava associada à ideia patriótica de "crescimento", "regeneração" do país e formação nacional em um contexto em que também se discutia sobre o fim do escravismo ou na condução dessas populações aos conchavos políticos (CARVALHO, 1996).

Hebe Mattos (2004) aponta que cidadania foi uma noção construída no Brasil ao longo do século XIX "em estreita relação com o dilema teórico entre liberalismo e escravidão". Para a vida eleitoral, foi adotado o voto censitário de três formas: "cidadão passivo" (sem renda suficiente para ter direito a voto), o "cidadão ativo votante" (com renda suficiente para escolher, através do voto, o colégio de eleitores), e o "cidadão ativo eleitor e elegível". E, em termos sociais, Mattos (2000) afirma que "virtudes e talentos" dos próprios escravos - ou, em outras palavras, a politização cotidiana de suas ações - desempenharam papel preponderante, seja para a aprovação da Lei do Ventre Livre, seja para a abolição final do cativeiro, sem indenização, em 1888.

Pensando na relação entre educação e voto, Sousa interpreta a reforma de 1870 com artigos úteis à preparação "[...] do cidadão eleitor para atuar política e juridicamente, tendo a instrução como a base de qualquer nação moderna, civilizada e o caminho para assegurar instituições políticas sólidas" (SOUSA, 2006, p. 202). Por esse motivo, também é possível compreender a ampliação de oportunidades educacionais da época na formação das primeiras letras. $\mathrm{O}$ estabelecimento de uma medida educacional como essa reforma é importante para pensarmos que as organizações educacionais estão, também, entre os objetivos da política de cada época, sejam os declarados em discursos para o bem do país e de sua população, sejam para os interesses em poder e vantagens financeiras, nem sempre declaradas explicitamente.

Miguel Luiz da Conceição (2007) faz uma leitura da reforma de 1870, buscando analisar de que forma grupos das camadas "populares" foram contemplados por esse regulamento, verificando a "dimensão política que regia os macro interesses presentes em tal medida" (p. 57). Ele acredita que a ideias de "desenvolvimento" exigidos naquele período dependiam da melhor instrução para $\mathrm{o}$ povo e não apenas a uma elite dirigente. $\mathrm{O}$ historiador aponta que era preciso cuidar logo dos que seriam responsáveis pela nação: as crianças e os jovens adultos, além também de ampliar a educação pela inserção de outras "categorias sociais da época", a exemplo dos libertos e ingênuos. Ele indica que a regulamentação baiana de 1870 fortaleceu a importância das primeiras letras, que tinham considerável significado para a mudança da situação da instrução, principalmente, o alto índice de analfabetismo, pelo aumento de possibilidades de escolarização (CONCEIÇÃO, 2007).

A direção da Instrução Pública regida por João Vitor de Carvalho em 1872 apresentava expectativas semelhantes às da direção anterior quanto aos resultados das escolas noturnas e apontou a criação delas como uma decisão muito acertada:

[...] tão necessários aos que ocupados durante o dia em ganhar os meios de subsistência, não têm o tempo preciso para esclarecer o espírito, espancando as trevas que os cercam, ainda são eles em pequeno número no Brasil, mas é certo que tão boa semente vai produzindo seus frutos, pois tais cursos aumentam de dia para dia, sendo notável a concorrência dos alunos, que neles encontram o pão de espírito. A criação das aulas noturnas para trabalhadores fora uma ação muito acertada, pois se tratou de uma ideia que tem sido geralmente bem aceita. (HENRIQUES, 1872).

Com todo otimismo de João Vitor de Carvalho, ainda assim, segundo o Presidente provincial, João Antônio de Araújo de Freitas Henriques, a Instrução Pública na Bahia precisava melhorar a qualidade de ensino e daí uma nova proposta de reforma educacional. Os pontos eram quase os mesmos da reforma anterior; porém, houve mais critérios em cada um deles. 
A criação das escolas noturnas foi de tamanha repercussão que, na proposta de reforma educacional seguinte, em 1873, alguns critérios específicos sobre elas foram desenvolvidos, como a gratificação dos professores e a regulação da quantidade de pessoas matriculadas e das que frequentavam - fatores determinantes para a continuação dessas escolas. Nesse regulamento, ficou deliberado que seria pago, aos professores das escolas noturnas, a metade do ordenado das aulas diurnas. $\mathrm{E}$ isso foi de encontro às primeiras ideias sobre essas escolas e da educação imperial de 1827, pois era previsto que nenhuma forma educacional deveria gerar mais gastos que o previsto aos cofres públicos. Porém, acredita-se que, diante de muitas solicitações de gratificação e da quantidade de escolas noturnas que foram criadas, houve a deliberação de como seriam pagos os professores dessas aulas (CARVALHO, 1873).

Segundo Silva (1999, p. 90), a questão de solicitação de pagamentos de professores já "era algo comum na vida da educação baiana", geralmente, era para o provimento mobiliário destinado às escolas de primeiras letras "[...] que derivavam também da Lei de 16 de junho de 1832, a qual permitiu que os professores pudessem pleitear junto à presidência da província $\mathrm{o}$ aparelhamento de suas aulas". Para o autor, o atendimento às solicitações dos professores era problemático. Eles necessitavam fazer vários pedidos, inclusive com o mesmo teor, e, mesmo assim, não tinham garantido o seu deferimento. Pediam valores para o pagamento de mobília, aluguel de casa escolar e gratificação, com as escolas noturnas não foi diferente - do tempo de sua fundação até os finais do Império.

Quanto ao pagamento do professor e da casa escolar, o Decreto Imperial de 15 de outubro de 1827 estabeleceu que estes seriam da ordem de 300 mil reis anuais para os professores de primeiras letras. "Também caberia ao professor com este salário alugar casa às suas custas para estabelecer sua aula, o que motivou o funcionamento da aula na própria residência do professor" (SILVA, 1999, p. 137). Essa informação ajuda a compreender a grande quantidade de pedidos de pagamento, tanto de honorários docente, quanto de estabelecimento e manutenção de escolas em todos os turnos, apesar de que as noturnas tinham um gasto além, o da iluminação.

A reforma de 1873 também intensificou a ideia de fiscalização do trabalho docente, através da inspeção de aulas. A figura do inspetor passou a ter, além atribuição de visitar as escolas da província, a assistir a uma sessão de cada escola, bem como cobrar mapas de aulas. Essas medidas eram para verificar a vida escolar dos alunos, se os professores cumpriam seus deveres e se tinham assiduidade (COUTO, 1873).

Quanto à qualificação e à habilitação dos professores, a proposta de reforma de 1873 fortaleceu a de 1870. Em um dos primeiros artigos, estava posto que somente poderiam exercer o magistério público os cidadãos brasileiros que provassem perante o diretor geral da Instrução Pública a maioridade legal, mediante certidão ou justificação de idade; ser considerado de moral ilibada e católico, por meio de atestado dos párocos; chefes de família dos lugares em que tivessem residido nos últimos três anos e não sofrer enfermidade incompatível com as funções do magistério, apresentando atestado médico. Além desses critérios, havia os de cunho intelectual como o exame que avaliava a capacidade profissional do candidato de forma oral e escrita, que ocorreria sob a presidência do diretor geral da Instrução Pública e perante os examinadores nomeados pelo governo (CARVALHO, 1873).

Em 1873, a situação da frequência também foi um dos pontos cruciais para a escolarização de adultos, pois era determinante para continuação ou não daquelas escolas que já não tinham a mesma ideia inicial diante das autoridades políticas e educacionais. Ela se tornou algo ainda mais discutido e ficou decidido, inicialmente, que seriam suprimidas as aulas noturnas que não tivessem 45 alunos de frequência ou 50 de matrícula. No mesmo ano, houve alteração da proposta devido ao aumento de ausência e a proporção passou a ser de 20 de frequência e 30 de matrícula. Inclusive, a diminuição do número de matrículas, com o passar dos anos, foi mais recorrente. Além da questão 
da quantidade de alunos, segundo o artigo 83 da reforma proposta em 1873, passou a ser proibida a matrícula dos alunos que padecessem de moléstias contagiosas, os que não tivessem sido vacinados e os escravizados (CARVALHO, 1873). Determinações que não significaram, necessariamente, que tenham sido seguidas à risca devido a um grande histórico de não cumprimento de lei nesse país e, além disso, pode ter existido resistência de escravizados em persistir e conseguir integrar-se a essas escolas na condição de alunos, como foi em alguns casos de escravizados, não só na Bahia mas em outras províncias (SCHUELER, 1997; LOPES, 2012; SILVA, 2005; SANTOS, 2016).

Em 1873, existiam oito escolas noturnas públicas na capital baiana: duas no Curato da Sé, com 176 alunos, uma com 92 e outra com 84, uma na freguesia de Santana com 103, uma na Conceição da Praia com 65 alunos, uma no Santo Antônio além do Carmo com 90, conforme relatório provincial de 1873. Já existiam várias escolas tanto na capital, como em outras regiões da província, mas para endossar seu otimismo com esse tipo de escolarização, o diretor Carvalho mais uma vez afirmou que:

Como se vê, não é desanimador o estado das escolas noturnas, e ao contrário, a frequência delas atesta que são procuradas. Convém, pois, auxiliar a criação de outras em mais lugares da província, pois será esse um meio profícuo de disseminar a instrução primária, fornecendo-a aqueles de nossos concidadãos, que, não podendo dispensar as horas do dia para estudar, só lhes restam a noite. Tendo estas escolas por fim dar instrução às nossas classes pobres e aos nossos operários, parece-me que estão no caso de merecer todo apoio e proteção dos governos ilustrados que reconhecem como a maior necessidade de instruir o povo. (CARVALHO, 1873, p. 21).

Conforme a afirmação de Carvalho, as escolas noturnas eram muito procuradas e úteis aos trabalhadores pobres, servindo para alcançar umas das metas públicas daquele período, a instrução para o povo ou instrução popular. Sara Dick aponta que a diferença significativa entre a reforma de 1873 para a de 1870 foi o aumento na centralização das regras docentes, a de 1873 foi mais focada nas exigências com o trabalho diário dos professores e na especificação dos critérios estabelecidos em 1870 (DICK, 2001). Portanto, o regulamento educacional de 1873 indica ser como mais um reforço da reforma de 1870, do que efetivamente inovações para a melhoria da Instrução Pública.

\section{Considerações finais}

Entre as medidas educacionais na Bahia na década de 1870, as escolas noturnas foram uma forma de possibilitar o acesso às primeiras letras a adultos que não estudaram na infância por qualquer motivo. $\mathrm{O}$ empenho em criar as escolas noturnas demonstra que o saldo sobre elas, nessa década, aponta para diversos aspectos sobres os significados que representaram em várias províncias brasileiras. Fica evidente que essas escolas estavam conectadas aos anseios políticos, sociais e econômicos da época. Portanto, formação nacional, combate ao analfabetismo, controle social, abolição da escravidão e promoção da cidadania foram as questões que enredaram o estabelecimento da escolarização noturna no Brasil no final do século XIX.

\section{Referências}

BRITO, J. L. A Abolição na Bahia (1880-1888). Salvador: CEB, 2003.

CARVALHO, J. M. de. A construção da ordem: a elite política imperial/O teatro das sombras: a política imperial. Rio de Janeiro: Editora da UFRJ; Relume Dumará, 1996.

CARVALHO, J. M. de. A construção da ordem: a elite política imperial / O teatro das sombras: a política imperial. Rio de Janeiro: Editora da UFRJ / Relume Dumará, 2003.

CHALHOUB, S. Cidade Febril: cortiços e epidemias na Corte imperial. São Paulo: Cia das Letras, 1996. 
Machado de Assis: O historiador. São Paulo: Companhia das Letras, 2003.

CONCEIÇÃO, M. L. da. "O aprendizados da liberdade": Educação de escravos, libertos e ingênuos na Bahia Oitocentista. 2007. $165 \mathrm{f}$. Dissertação (Mestrado em História) - Programa de Pós-Graduação em História, Universidade Federal da Bahia, Salvador, 2007.

COUTO, J. J. D', Relatório do Presidente da província, 1873, p1-5, http://brazil.crl.edu/bsd/ bsd/144/000075.html. Acessado em 11/04/2016.

DICK, S. M. “As políticas públicas para o ensino secundário na Bahia: o liceuprovincial. 18601890”. 2001. 289 f. Tese (Doutorado em Educação) - Programa de Pós-Graduação em Educação, Universidade Federal de Bahia, Salvador, 2001.

FONSECA, L. A. da. A escravidão, o clero e o abolicionismo. Recife: Editora Massangana, 1987.

HENRIQUES, J. A. de A. F. Relatório do Presidente da Província da Bahia, 1872, p. 1-23 http://brazil. crl.edu/bsd/bsd/143/000264.html. Acesso em: 10 abr. 2016.

LEAL, M. das G. de A. A Arte de ter um ofício (1872-1996): Liceu de Artes e Ofício da Bahia. Salvador: Liceu de Artes e Ofícios da Bahia, 1996.

MACCORD, M. Artífices da cidadania: mutualismo, educação e trabalho no recife oitocentista. Campinas: FAPESP; Ed Unicamp, 2012.

MARTINS, F. G. Relatório do Presidente da Província da Bahia, em 1869, http://brazil.crl.edu/bsd/ bsd/136/000030.html, p. 28. Acesso em: 09 abr. 2016.

MARTINS, F. G. Relatório do Presidente da Província da Bahia, em 1870, http://brazil.crl.edu/ bsd/bsd/139/000097.html, p. 139. Acesso em: 09 abr. 2016.

MATTOS, H. M. Escravidão e cidadania no Brasil Monárquico. 2. ed. Rio de Janeiro: Jorge Zahar, 2004.
MATTOS, I. R. de. O Tempo Saquarema: a formação do Estado Imperial. 5. ed. São Paulo: Editora Hucitec, 2004.

MENDONÇA, J. M. N. Entre a mão e os anéis: A lei dos sexagenários e os caminhos da abolição no Brasil. 2. ed. Campinas: Editora da Unicamp, 2008.

MOACYR, P. A Instrução e o Império. São Paulo: Cia Editora Nacional, 1939.

O GUAYACRU, 1 de fevereiro de 1851.Site: http://bndigital.bn.br/hemeroteca-digital/ e http://memoria.bn.br/DocReader/docreader. aspx?bib=709794\&pesq= Acesso em: 17 abr. 2016 .

SANTOS, J. C. dos. Escravizados e libertos nas escolas noturnas baianas no final do século XIX. 2016. Disponível em: <http://www.laplageemrevista. ufscar.br/index.php/REB/issue/view/9/showToc. 05/12/2016>. Acesso em: 10 mar. 2017.

SILVA, J. C. de A. O Recôncavo baiano e suas escolas de primeiras letras. (1827-1852): Um estudo do cotidiano escolar. 2009. 209 f. Dissertação (Mestrado em Educação) - Programa de Pós-Graduação em Educação, Universidade Federal da Bahia, Salvador, 1999.

SOUSA, I. C. J. de. Escolas ao Povo: experiências de escolarização de pobres na Bahia - 1870 a 1890. 390 f. Tese (Doutorado História) -Programa de PósGraduação em História, Pontifícia Universidade Católica de São Paulo, São Paulo, 2006.

SCHUELER, A. A. M. Educar e Instruir: A Instrução popular na corte Imperial - 1870 a 1889 . 1997. 241 f. Dissertação (Mestrado em História) - Programa de Pós-Graduação em História, Universidade Federal Fluminense, Niterói, 1997.

WILDBERGER, A. Os presidentes da Província da Bahia (1824-1889). Salvador: Tip. Beneditina, 1949. 